\title{
Um olhar qualitativo sobre as parcerias latentes em projetos educativos
}

\author{
Ana Rita Rodrigues ${ }^{1}$ \\ Carlos Marques² \\ Helena Reis ${ }^{3}$ \\ Miguel Maia
}

Resumo: Esse artigo retrata uma análise de projetos educativos de agrupamentos de escolas públicas, privadas e profissionais de um conselho situado no centro de Portugal com o intuito de compreender se os documentos espelham uma escola aberta à comunidade. Assim, pretende-se verificar se decorridos vários anos da existência de projetos educativos nas escolas, tais documentos refletem as parcerias com a comunidade e as operacionalizam. Trata-se, portanto, de um estudo de caso que se centra na análise de doze projetos educativos. A análise de conteúdo teve por recurso o software WebQDA. Verificou-se a impossibilidade de realizar uma linha de análise vertical comum a todo o corpus documental, dada a sua heterogeneidade estrutural. No entanto, pôde-se concluir que a existência de parcerias com a comunidade, ou a sua operacionalização, não são uma preocupação plasmada na generalidade dos projetos educativos analisados.

Palavras-chave: parcerias; comunidade; escola sem muros; projeto educativo.

\footnotetext{
1 Pós-graduada em Práticas Educativas em Inclusão pela Universidade do Estado de Minas e em Gênero e Diversidade na Escola pela Universidade Federal de Minas Gerais. Professora da Prefeitura Municipal de Belo Horizonte. E-mail: anarita.rvcm@ua.pt

${ }^{2}$ Mestre em Gestão da Qualidade pela Universidade Estadual de Campinas (Unicamp). Professor do Centro Universitário da Fundação Educacional Inaciana (FEI).

3 Professora no Instituto Federal de Educação, Ciência e Tecnologia Farroupilha (IFFAR).

${ }^{4}$ Mestre em Ciências da Educação na Universidade do Minho, Portugal.
} 


\title{
A qualitative perspective upon latent partnerships in educational projects
}

\begin{abstract}
This article presents an analysis of educational projects of public, private, and professional school groups located in central Portugal, aiming to understand if the documents mirror schools which are opened to the community. Thus, several years after the beginning of these educational projects, this study intends to verify if these documents reflect the referred partnerships with the community and operationalize them. Therefore, this is a case study that focuses on the analysis of twelve educational projects. The content analysis was carried based on results achieved through webQDA software. Due to the heterogenous structure found, it was impossible to perform a vertical analysis line that would be common to the whole documentary corpus. However, it is possible to conclude that the existence of partnerships with the community, or their operationalization, is not a concern reflected in most of the educational projects analyzed.
\end{abstract}

Keywords: partnerships; community; school without walls; educational project

Apontando para uma conceptualização generalizada, e percebendo as diferentes mutações do conceito ao longo dos tempos, a eficácia da escola remete, hoje, para a diversidade de caminhos nos quais a instituição escolar pode enveredar para responder às exigências do mundo atual. Assim, educar para a qualidade pode significar implementar nas escolas dinâmicas de cooperação com o exterior e abrir portas para a comunidade. Essa retroalimentação entre os parceiros e a escola incita a trocas de experiências, ricas para todos os intervenientes envolvidos e indicia uma atitude reflexiva.

Assim, na construção dos documentos orientadores das instituições escolares, devem ser tidas em conta as parcerias que possam ser estabelecidas com entidades externas, sejam elas públicas ou privadas. É importante que os Projetos Educativos (PE) reproduzam fielmente a ação da escola e demonstrem, com clareza, os benefícios e as potencialidades das atividades com as entidades parceiras.

Neste sentido, surge o propósito deste artigo: estudar os PEs dos agrupamentos de escolas, bem como escolas não agrupadas de um conselho situado no centro de Portugal, de forma a perceber se esses documentos refletem essa desejável abertura ao exterior iniciada por John Bremer ${ }^{5}$ e, sendo verificada, perceber em que medida e de que forma essa ligação é feita.

5 John Bremer é um educador e filosofo socrático. Criou em 1968 o “Programa Parkway”, a primeira escola aberta à comunidade. 


\section{Contextualização teórica}

\section{Quadro legal do projeto educativo}

A busca etimológica do termo projeto e o seu caráter polissémico não representa para este estudo uma preocupação de abordagem já que estes foram elementos largamente explorados (COSTA, 1997) e o seu uso não é recente. Partindo da expressão de Herbert Simon (1981, p. 193), "projeta quem quer que conceba cursos de ação com o objetivo de transformar situações existentes em situações preferidas", traça-se o pano de fundo do estudo aqui apresentado, focalizando o termo 'projeto' no uso exclusivo em torno da educação e da escola e como concretização de uma vontade transformadora da realidade existente na escola em algo melhor, a Simon chama de "preferido".

A acompanhar a chamada reforma do sistema educativo, nos anos 80 , surge o conceito de $\mathrm{PE}$, ainda que não expresso na Lei de Bases do Sistema Educativo (Lei n. ${ }^{\circ}$ 46/86 de 14 de outubro). De fato, a massificação da escola e a evolução social incutiram na escola e nos professores papéis que até então não Ihes eram reconhecidos, muito menos imputados. Fala-se da necessidade de estender a sua ação para além do simples cumprimento paradigmático de um currículo prescrito e universal.

O reconhecimento da importância do contexto, das particularidades geográficas, sociais, econômicas e culturais e a sua influência na vida e no percurso escolar fazem com que as características das comunidades sejam tidas como um elemento ativo na vida da escola com repercussões nos seus agentes, influenciando, claramente, o percurso escolar dos elementos da comunidade. Começa a acreditar-se que a imposição de modelos estandardizados e uniformizados de ação "na suposição de que a justiça está em dar o mesmo a todos de modo igual não se adequa ao diagnóstico da individualidade de cada criança ou jovem" (COSTA, 1997, p. 36). Neste sentido, surge a necessidade, por um lado, da valorização e da conquista, por outro, da autonomia. Sem autonomia as escolas não conseguem atender pedagogicamente à heterogeneidade dos discentes e aos diferentes meios onde as comunidades educativas se inserem.

Esta consciência de que há uma "inadequação intrínseca do sistema burocrático centralizado à gestão escolar pedagógica" (FORMOSINHO, 1984, p. 104) levou, em finais dos anos 80, a ser publicado o DL n. ${ }^{\circ}$ 43/89 de 3 fevereiro onde se pode assistir a uma associação direta entre PE e a questão da autonomia das escolas. No preâmbulo deste decreto de lei pode-se ler que há um esforço para "desconcentração de funções e de poderes", procurando alargar a "capacidade de diálogo com a comunidade em que se inserem", visando o "reforço da autonomia da escola". Autonomia essa que se concretiza através da "elaboração de um PE próprio, constituído e executado de forma participada, dentro de princípios da responsabilização dos vários intervenientes na vida escolar e de adequação a características e recursos da escola e às solicitações e apoios da comunidade em que se insere". 
Assiste-se à necessidade, imposta por força de lei, de cada escola se tornar palco de decisões, como que alargando, ainda que de forma tímida, o laço que a prende a um "Estado regulador que, em nome da eficácia e da qualidade (e reconhecendo a incapacidade da gestão centralizada) vai transferir para a periferia, para o local, para os atores, espaços significativos das suas competências anteriores" (COSTA, 1997, p. 37). Neste sentido, é dado um passo, ainda que tímido, como se refere anteriormente, mas importante, na busca da descentralização e da acentuação da autonomia das escolas. Esta traduz-se na "capacidade de elaboração e realização de um projeto educativo em benefício dos alunos e com a participação de todos os intervenientes no processo educativo", como se pode ler no n. ${ }^{\circ}$ do artigo 2. ${ }^{\circ}$ do $\mathrm{DL} \mathrm{n} .^{\circ} 43 / 89$ de 3 de fevereiro.

Assim, o PE "devia permitir responder às solicitações da comunidade, exigindo a sua participação na vida da escola, e promover um diálogo dialógico e democrático" (MAGALHÃES \& MORGADO, 2017, p. 394). No entanto, de acordo com o DL n. ${ }^{\circ} 43 / 89$, n. 2 do artigo $2 .^{\circ}$, o PE traduzia-se, essencialmente, pela "formulação de prioridades de desenvolvimento pedagógico, em planos anuais de atividades educativas e na elaboração de regulamentos internos para os principais setores e serviços escolares".

É neste sentido que Costa (2004, p. 88) refere a passagem "da ilusão do Decreto 43/89 à realidade do Despacho 8/SERE/89". Este despacho reconhece no próprio preâmbulo constituir-se como regulamento provisório "enquanto os conselhos pedagógicos não dispuserem de regulamento adequado à função que devem desempenhar numa escola com mais autonomia e maior responsabilidade", atribuindo ao Conselho Pedagógico a competência, de acordo com o ponto 3.11., de "desencadear ações e mecanismos para a construção de um projeto educativo de escola". "A partir desta altura, as escolas foram pressionadas pelas Direções Regionais da Educação e pelos Serviços de Inspeção a elaborarem os seus projetos educativos" (COSTA, 2003, p. 91). No entanto, segundo o mesmo autor, na altura em que tais diretrizes surgem,

tornou-se improcedente, pois, num quadro de ausência significativa de autonomia, os projetos educativos converteram-se em meros artefactos para a vida organizacional e, enquanto documentos, num conjunto de intenções genéricas sem definição de prioridades, sem estratégias de operacionalização, quedando-se, na maior parte das vezes, na caracterização descritiva da escola (COSTA, 2003, p. 91).

Foi somente na década de 90, com a publicação do DL 172/91 de 10 de maio, que se tornou expressa a obrigatoriedade legal da existência do PE nas escolas, ainda que somente tenha sido "aplicado, em regime de experiência limitada, a 49 escolas e 5 áreas escolares" (DELGADO \& MARTINS, 2001 , p. 23). O diploma descreve no seu preâmbulo, considerado significativo para o estudo que se pretende fazer, que o Decreto de Lei, 
concretiza os princípios de representatividade, democraticidade e integração comunitária [...] pretende assegurar à escola as condições que possibilitam a sua integração no meio em que se insere. Exige o apoio e a participação alargada da comunidade na vida da escola. [...] Garante, simultaneamente, a prossecução de objetivos educativos nacionais e a afirmação da diversidade através do exercício da autonomia local e a formulação de projetos educativos próprios.

Sem dúvida que o DL 172/91 de 10 de maio dá uma contribuição importante para a identidade do $P E$, na medida que o distancia de outros documentos importantes na vida da escola, como o regulamento interno, o plano de atividades ou o projeto orçamental, como se pode ler no artigo $8 .^{\circ}$ quando se refere as competências do então chamado Conselho de Escola. No entanto, Afonso, Estevão e Castro (1999, p. 57), abordam a "existência frequente de desarticulações inter e intradocumentos".

Pela primeira vez, são implicados no PE três estruturas orgânicas: (1) de acordo com o artigo 32. , o conselho pedagógico, enquanto órgão técnico e consultivo de "coordenação e orientação educativa", a quem compete proceder à elaboração do $\mathrm{PE}$; (2) ao diretor executivo enquanto órgão unipessoal de "administração e gestão do estabelecimento de ensino nas áreas cultural, pedagógica, administrativa e financeira", a quem compete encaminhar a proposta do conselho pedagógico para o conselho de escola, de acordo com o artigo 17..$^{\circ}$ e, (3) ao conselho de escola, enquanto órgão de direção da escola, a quem compete aprovar o projeto educativo como descreve o artigo 8. ${ }^{\circ}$.

Em meados dos anos 90, Costa (1997, p. 198-199) realizou um estudo empírico sobre a concepção e desenvolvimentos de PE e refere que,

\begin{abstract}
a imagem que nos parece mais adequada ao documento em estudo e aos procedimentos que o rodearam é, globalmente, a do projeto como ritual legitimador já que este projeto educativo não chegou a vincular as práticas organizacionais por nós observadas, vindo a cair no destino comum de outros procedimentos escolares ritualizados. [...] Tratou-se, portanto, de um artefacto que contribuiu para avolumar o conjunto dos elementos de formalização estrutural desta organização escolar, cumprindo, no entanto, à semelhança do ocorrido na escola anterior, [...] uma dupla função: por um lado, dar resposta às exigências e expectativas sociais, políticas, administrativas e legais [...] e, por outro lado, legitimar, quer a razão de ser [...] desta iniciativa, quer a imagem de competência e de qualidade da escola.
\end{abstract}

Costa (2004, p. 95) concluiu a este respeito que,

se esteve mais perante uma inovação instituída, não interiorizada, em que o projeto educativo assume essencialmente um valor simbólico e ao serviço da legitimidade externa da escola, do que propriamente perante a construção de uma verdadeira identidade e especificidade organizacional

O PE parece adquirir uma revitalização nos finais dos anos 90 com a publicação do DL 115A/98 de 4 de maio, que aprova o regime de autonomia, administração e gestão dos estabelecimentos públicos da educação pré-escolar e dos ensinos básico e secundário, bem como dos respetivos agrupamentos. O seu preâmbulo afirma que o PE é uma forma de capacitar as escolas "a assumir, em 
grau mais elevado, a autonomia", permitindo a elas "gerir melhor os recursos educativos de forma consistente". Para o presente estudo importa salientar o texto do preâmbulo deste decreto de lei que indica que a escola deve desenvolver a sua autonomia "a partir da comunidade em que se insere". Por autonomia entende-se,

o poder reconhecido à escola pela administração educativa de tomar decisões nos domínios estratégico, pedagógico, administrativo, financeiro e organizacional, no quadro do seu projeto educativo e em função das competências e dos meios que lhe estão consignados (DL 115-A/98 artigo $3 . .^{\circ}$ n. ${ }^{\circ}$ ).

No mesmo diploma, na alínea a) do mesmo número, define-se PE como,

o documento que consagra a orientação educativa da escola, elaborado e aprovado pelos seus órgãos de administração e gestão para um horizonte de três anos, no qual se explicitam os princípios, os valores, as metas e as estratégias segundo os quais a escola se propõe cumprir a sua função educativa (DL 115-A/98 artigo $3 .^{\circ}$ n. ${ }^{\circ}$ 1).

Assim, também se entende o PE como documento central, do qual dependem outros, como o Plano Anual de Atividades. Na opinião de Costa (2004, p. 97), essa foi "uma das primeiras definições mais esclarecedoras deste documento". No entanto, após a realização de um estudo levado a cabo por Barroso (2001) a fim de avaliar o impacto da implementação do DL 115-A/98 de 4 de maio, concluiu-se que "para quem imaginava que o DL 115-A/98 era muito mais do que uma simples remodelação formal da gestão escolar, os resultados alcançados, no final de dois anos, são frustrantes [...] era possível ter feito mais" (BARROSO, 2001, p. 21).

Portanto, o curto caminho percorrido ao nível da autonomia foi proporcional ao desenvolvimento ocorrido no que concerne ao PE pois, tal como mencionado no diploma, o desenvolvimento deste depende dos acordos efetuados ao nível dos contratos de autonomia. Decorridos mais de meia década da publicação do diploma, Costa (2004) não hesitava em afirmar acerca da publicação desta legislação que "os contratos de autonomia continuam a ser, à exceção de diversos conteúdos dos discursos com que nos brindam os políticos, uma miragem" (COSTA, 2004, p. 99).

Justificava-se assim uma alteração de políticas. No entanto, a publicação do DL 6/2001 parece trazer algum retrocesso na medida em que coloca a tônica educativa, de forma algo redutora, exclusivamente na vertente curricular e, como se lê no seu preâmbulo, de forma a desenvolver-se a autonomia das escolas "estabelece-se que as estratégias de desenvolvimento do currículo nacional, visando adequá-lo ao contexto de cada escola, deverão ser objeto de um projeto curricular de escola, concebido, aprovado e avaliado pelos respetivos órgãos de administração e gestão". Salienta-se que este conceito de projeto curricular é completamente ignorado no DL 115-A/98.

Foi neste quadro legal que as escolas foram convivendo com a tensão autonomia, educação e currículo durante uma década, até à publicação do DL 75/2008 de 22 de abril. Assim, assiste-se a uma 
reinterpretação da Lei de Bases do Sistema Educativo onde se incita, no artigo 3.․, alínea g), a "um elevado sentido de participação das populações, uma adequada inserção no meio comunitário e níveis de decisão eficientes".

Este decreto de lei reforça a participação de elementos externos à escola, nomeadamente através da participação no órgão de direção estratégica das escolas, agora chamado de Conselho Geral. Dessa forma, assistimos a um reforço da participação dos pais, da autarquia e da comunidade, nomeadamente, como se lê no n. ${ }^{\circ} 6$ do artigo 12. "representantes de instituições, organizações e atividades de carácter económico, social, cultural e científico". A nova estrutura organizacional e legal da escola coloca no PE uma centralidade da qual depende a sua orientação educativa, tal como se lê no artigo $9 .^{\circ}$, onde se diz que é "elaborado e aprovado pelos seus órgãos de administração e gestão [...] no qual se explicitam os princípios, os valores, as metas e as estratégias segundo os quais o agrupamento de escolas ou escola não agrupada se propõe cumprir a sua função educativa".

No ano seguinte, foi publicada a primeira alteração ao DL 75/2008, a 11 de setembro de 2009 com o Decreto-Lei n. ${ }^{\circ}$ 224/2009, alteração essa que não trouxe mudanças significativas. Contudo, volvidos quatro anos da sua publicação original, aconteceu a segunda alteração com a publicação do DL no 137/2012, de 2 de julho, a qual já trouxe algumas alterações ao nível da autonomia. Constata-se, como se pode ler no seu preâmbulo, a vontade de reforçar progressivamente a autonomia e a maior flexibilização organizacional e pedagógica das escolas e "o reforço da abertura à comunidade". É salientada a vontade de "reorganização da rede escolar através do agrupamento e agregação de escolas de modo a garantir e reforçar a coerência do projeto educativo e a qualidade pedagógica das escolas," reforçando as competências do conselho geral, a conferência ao diretor de maior legitimidade para o exercício da função e a responsabilização dos detentores de cargos de direção e gestão de topo e intermédia.

Ter um PE "contextualizado, consistente e fundamentado", agora elaborado pelo Conselho Pedagógico (artigo 33..$^{\circ}$ é requisito a ter em conta, segundo o n. 3 do artigo $57 .{ }^{\circ}$, para ser celebrado um contrato de autonomia. Assim, enfatiza-se a importância do PE enquanto instrumento de autonomia da escola e reforço da exigida abertura à comunidade.

\section{Mutualismo e cooperação numa escola sem muros}

No final da década de 60, com a grave crise de ensino que se vivia na época, John Bremer criou, em Filadélfia, o "Programa Parkway" - o primeiro PE inovador onde se "destruíram" as paredes da escola. Neste projeto, os alunos passaram a participar na definição dos próprios programas de estudo, as aulas passaram a acontecer em vários locais da cidade promovendo a utilização de instalações culturais como museus e bibliotecas, começaram a ser valorizadas pelos professores não só as avaliações quantitativas como também as avaliações qualitativas dos alunos (BREMER \& MOSHINGISHER, 1975). 
Os mesmos autores afirmam que, desde então, a parceria com as famílias deixou de ser o único objetivo da gestão escolar. Passou a ser também importante para o desenvolvimento dos alunos a construção de uma relação positiva com a população em torno. Na sociedade atual, a educação tem saído cada vez mais dos muros da escola alcançando outros espaços sociais. Neste sentido, atualmente, a organização escolar possui objetivos específicos (educacionais) voltados para a concretização do processo ensino e aprendizagem. Nessa direção, para Parro (2011, p. 34),

O erro básico que persiste na organização das escolas é a omissão da especificidade do seu trabalho e a assunção de um modelo de estrutura adequado às empresas privadas, em geral produtoras de bens e serviços que, na sociedade capitalista, têm objetivos antagônicos ao do empreendimento educacional".

Nessa perspectiva, o mesmo autor afirma ainda que a escola necessita ser compreendida como uma instituição que reúne um conjunto de agentes sociais capazes de formular uma prática social intencional com objetivos, meios e fins planejados antecipadamente, que revela distintas visões de mundo, homem e de sociedade (PARRO, 2011).

A intenção de criar novas dinâmicas escolares através das parcerias com a comunidade promove a qualidade da prestação do serviço e a melhoria dos resultados (LEITE, PRECIOSA, MOURAZ, \& SAMPAIO, 2015). Os mesmo autores afirmam que existe uma atenção cada vez maior por parte das escolas e dos professores em desenvolver ações que liguem a escola à comunidade, promovendo dinâmicas educacionais que vão para além das fronteiras organizacionais e, ainda, identificam os três tipos de efeitos das parcerias: a adesão a projetos nacionais e/ou internacionais, a inovação curricular e o alargamento da oferta formativa.

As escolas valorizam cada vez mais as parcerias principalmente nas áreas da saúde, apoio social e apoio psicológico "que se interligam e contribuem para fortalecer a relação da escola com o local em que está inserida" (LEITE et al., 2015, p. 846). Ao mesmo tempo, essas parcerias potencializam a valorização da escola na comunidade, sendo reconhecido a sua contribuição para o desenvolvimento social. Esta relação escola-comunidade deve ser uma relação de mutualismo em que a escola se beneficia com as parcerias envolvidas, mas ao mesmo tempo, abre os seus portões, por vezes, para a cedência do seu espaço à comunidade, mas, essencialmente, para a participação da comunidade na vida acadêmica.

\section{Metodologia}

Numa tentativa de compreensão holística, a finalidade do estudo pretende, através da análise de $\mathrm{PE}$, aprofundar o conhecimento sobre as relações e parcerias da escola com o seu exterior. De igual forma, procura-se entender se as relações externas retratadas nos documentos têm representatividade nas diversas instituições de ensino do estudo e de que forma elas são operacionalizadas. Neste 
contexto, e decorrentes dos objetivos traçados, pretende-se dar resposta às questões de investigação: "De que forma os projetos educativos transparecem as relações com a comunidade? Em que medida essas relações se replicam e se operacionalizam nas diferentes instituições de ensino?".

O corpus documental em análise recaiu em documentos disponíveis na internet. Os doze projetos educativos incidem no período de 2014 a 2021 e foram recolhidos nos diferentes sites das instituições de ensino. Foi critério de inclusão para o estudo serem documentos de agrupamentos de escolas ou de escolas não agrupadas pertencentes ao mesmo conselho. Contextualizando, e no que diz respeito ao ensino público, referem-se os sete agrupamentos de escolas, que abrangem jardins infantis, escolas do $1 .^{\circ}$ ciclo, escolas do $2 .^{\circ}$ e $3 .^{\circ}$ ciclo e escolas secundárias. Constituem ainda o corpus documental os PEs dos dois estabelecimentos do ensino profissional e dos três estabelecimentos de ensino privado com $1 .^{\circ}, 2 .^{\circ}$ e $3 .^{\circ}$ ciclo desse conselho.

No estudo apresentado, e como referido anteriormente, o caso selecionado concretiza-se no conjunto de doze PEs. O referencial metodológico do estudo caso é particularmente utilizado nas ciências sociais e em contexto educacional e, como refere Coutinho (2019), está integrado num fenômeno complexo, em ambiente real. Procura-se estudar, de forma aprofundada e detaIhada, uma situação específica e de pequenas dimensões - o caso. $O$ caso pode assumir-se como um indivíduo, uma comunidade, um processo, um objeto, um acontecimento ou uma situação (COUTINHO, 2019; YIN, 2015).

O presente estudo é de natureza exploratória, enquadrado no paradigma interpretativo, assumindo-se como uma investigação qualitativa para uma observação mais subjetiva, alvo de interpretação e de análise de conteúdo sobre os documentos. Salienta-se o paradigma interpretativo que defende uma investigação de natureza holística e construída, interna e subjetiva, em que o investigador assume um papel seletivo. Por outro lado, para Coutinho (2019), através da participação do investigador, quer na recolha controlada como na análise dos dados ou na avaliação dos processos, é permitido que sejam levantadas questões que possam contribuir para a construção de teorias e procedimentos - suportes fundamentais nas práticas educativas dos professores e gestores escolares, nomeadamente quando estes elaboram os PEs das suas escolas.

Como refere Bardin (2009), a análise de conteúdo é mais do que um instrumento, pois incorpora todo um "conjunto de técnicas de análise das comunicações" (p. 33). Assim, a análise de dados possibilita organizar e sumariar os dados de forma que sejam dadas respostas ao problema de investigação (DIAS, 2009). A análise pode incidir sobre certos elementos do registro, procurando revelar as representações sociais, sobre a sua forma,examinando o encadeamento do discurso, ou numa análise estrutural sobre as relações entre os elementos que constituem os documentos em análise, verificando de que forma os constituintes da mensagem estão dispostos (QUIVY \& CAMPENHOUDT, 2008). 
Desta forma, e quanto à análise de conteúdo do corpus documental latente, ela foi realizada com recurso do software para análise qualitativa - o WebQDA. O programa permite o tratamento de dados não numéricos e possibilita aos investigadores trabalhar de forma colaborativa uma vez que se trata de uma plataforma online ${ }^{6}$. O processo de codificação foi partilhado pelos quatro investigadores envolvidos no estudo e decorreu em três fases distintas: a primeira, com a leitura global do corpus latente; a segunda, com a codificação no software WebQDA e a terceira, com a verificação dos resultados da codificação da fase 2 .

As categorias da grelha de análise, validadas por perito em metodologia, derivam do quadro teórico e das questões de investigação e representam um "grupo de elementos (unidades de registo) sob um título genérico" (BARDIN, 2009, p. 145) mediante as particularidades análogas encontradas entre esses elementos. Assim, apresentam-se na Tabela 1 as categorias e subcategorias que serviram de suporte à criação da grelha de análise de conteúdo do estudo. Para melhor compreensão da codificação realizada no WebQDA, descreve-se aqui os códigos árvore classificados e posteriormente analisados:

- Representação externa no Conselho Geral: todas as entidades privadas de caráter econômico, social, cultural/desportivo e científico, as instituições públicas (no âmbito social, saúde, segurança pública, entre outros) e o município (Câmara Municipal e Juntas de Freguesia) que tenham assento no Conselho Geral dos Agrupamentos de Escola.

- Parceria/Protocolos: relações da escola como o exterior, representadas através de parcerias ou protocolos com os organismos públicos, as entidades privadas e o município. Identificação das fragilidades e potencialidades relacionadas com as parcerias e referidas no corpus documental.

- Missão/Visão: referências no texto da missão e/ou visão da instituição escolar que mostram a relação da escola com o exterior.

- Objetivos: objetivos traçados no corpus documental que visam ou abordam a relação da instituição escolar com o exterior.

- Planos/ações: planos ou ações provenientes de dinâmicas que envolvam parceiros, ou que sejam resultantes da aplicação de protocolos com entidades externas.

- Tipologia dos AEs ou escolas não agrupadas: catalogação das instituições escolares segundo os grupos 'Ensino Público', 'Ensino Privado' e 'Ensino Profissional'.

6 Disponível em: www.webqda.net. Acesso em: 22 out. 2020. 
Tabela 1 - Categorias e subcategorias da grelha de análise de conteúdo

\begin{tabular}{|c|c|}
\hline Categoria & Subcategoria \\
\hline \multirow{6}{*}{ Representação externa no Conselho Geral } & Município \\
\hline & Instituições/Organizações \\
\hline & Entidades - atividades de carácter económico \\
\hline & Entidades - atividades de carácter social \\
\hline & Entidades - atividades de carácter cultural/desportiva \\
\hline & Entidades - atividades de carácter científico \\
\hline \multirow{8}{*}{ Parcerias/Protocolos } & Município \\
\hline & Instituições/Organizações \\
\hline & Entidades - atividades de carácter económico \\
\hline & Entidades - atividades de carácter social \\
\hline & Entidades - atividades de carácter cultural/desportiva \\
\hline & Entidades - atividades de carácter científico \\
\hline & Fragilidades/Ameaças/Fraquezas \\
\hline & Potencialidades/Pontos fortes/Oportunidades \\
\hline Missão/Visão & Missão/Visão e sua relação com o exterior \\
\hline Objetivos & Objetivos e sua relação com o exterior \\
\hline Planos/ações & Planos direcionados para a relação com a comunidade \\
\hline \multirow{3}{*}{ Tipologia dos AE ou Escolas não agrupadas } & Ensino público \\
\hline & Ensino privado \\
\hline & Ensino profissional \\
\hline
\end{tabular}

Fonte: elaborado pelo autor

\section{Análise e discussão dos resultados}

Da análise efetuada ao corpus documental latente, e com base no software webQDA, pode enunciar-se um conjunto de considerações. A primeira leitura que sobressai é que, em sentido oposto ao plasmado na lei, particularmente nos DL n 43/89 de 3 de fevereiro, 172/91 de 10 de maio, 75/2008 de 22 de abril e 137/2012 de 2 de julho, nem todos os agrupamentos indicam a existência de parcerias nos seus PEs; apenas $67 \%$ o fazem, sendo que $17 \%$ do total referem a existência de apenas uma ou duas parcerias. Além disso, $42 \%$ demonstram a existência de parcerias com entidades pertencentes à maior parte das subcategorias predefinidas, ou seja, com um leque abrangente de entidades.

Em geral os agrupamentos públicos fazem referência nos seus PEs a mais parcerias que as restantes. Apenas as parcerias com entidades de cariz econômico são dominadas pelo ensino privado, particularmente por uma das escolas. Embora sem ocorrências na totalidade dos PEs, o Município e a Universidade são as parcerias com maior incidência, complementadas pelas Juntas de Freguesia e a Santa Casa da Misericórdia. Somente a universidade é referenciada como parceiro em várias tipologias de ensino. Tal como é referido no enquadramento teórico, considera-se que o município e a 
universidade são tão evidenciados nos PEs pelo fato da escola criar uma relação e se interligar com o local onde está inserida.

Como dito anteriormente, se tomarmos somente o número de ocorrências observadas, poderá afirmar-se que, majoritariamente, as escolas privadas fazem protocolos com entidades de cariz econômico; no entanto a totalidade dessas ocorrências está relacionado apenas com uma única escola.

Acresce dizer que $66 \%$ dos PEs das escolas privadas referem a existência de parcerias, sendo a maior parte delas estabelecidas com entidades de caráter cultural/desportivo e de caráter científico.

Já no que diz respeito a agrupamentos públicos, as parcerias referidas nos PEs, embora concentradas em apenas quatro agrupamentos, são estabelecidas em maior número com entidades de cariz científico, ao contrário do que afirmam Leite et al., (2015).

A distribuição da existência de parcerias com instituições/organizações públicas tem maior significância nos PEs dos agrupamentos públicos (71\%). Das duas escolas profissionais observadas, apenas uma refere a existência de parcerias, majoritariamente com instituições/organizações públicas.

Terminada a análise desta secção, reforça-se que há PEs sem qualquer menção a parcerias e que há registo de uma única parceria com entidades de cariz econômico, ou seja, com empresas. A seguinte tabela (Tabela 2) contribuirá para uma melhor interpretação dos dados recolhidos no que concerne a parcerias relacionadas com a relação com a comunidade envolvente.

Tabela 2 - Ocorrências de parcerias entre escola e comunidade envolvente

\begin{tabular}{|c|c|c|c|c|c|c|}
\hline \multirow[b]{2}{*}{ 㟔 } & & \multicolumn{5}{|c|}{ Estabelecimentos de cariz } \\
\hline & 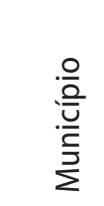 & 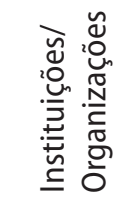 & 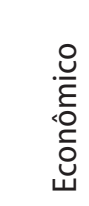 & $\begin{array}{l}\bar{\pi} \\
\overline{0} \\
\sim\end{array}$ & 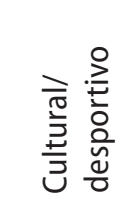 & 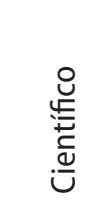 \\
\hline $\mathrm{Ag} 1$ & 3 & 3 & 0 & 2 & 2 & 4 \\
\hline Ag2 & 0 & 0 & 0 & 0 & 0 & 0 \\
\hline Ag3 & 2 & 3 & 0 & 5 & 3 & 5 \\
\hline Ag4 & 2 & 3 & 1 & 3 & 3 & 3 \\
\hline Ag5 & 0 & 0 & 0 & 0 & 0 & 0 \\
\hline Ag6 & 2 & 1 & 0 & 0 & 0 & 1 \\
\hline Ag7 & 0 & 1 & 0 & 0 & 0 & 0 \\
\hline Pri1 & 2 & 3 & 18 & 3 & 2 & 2 \\
\hline Pri2 & 0 & 0 & 0 & 0 & 1 & 1 \\
\hline Pri3 & 0 & 0 & 0 & 0 & 0 & 0 \\
\hline Prof1 & 0 & 0 & 0 & 0 & 0 & 0 \\
\hline Prof2 & 0 & 5 & 1 & 2 & 0 & 2 \\
\hline
\end{tabular}

Fonte: elaborado pelo autor 
A maior parte dos agrupamentos públicos (57\%) não apresenta a constituição do Conselho Geral (DL 75/2008 de 22 de abril) nos seus PEs. Os dados obtidos a esse respeito são muito díspares e não permitem tirar grandes conclusões. Refere-se apenas a existência de ocorrências em todas as subcategorias de parceiros; apesar disso, não é possível nomear uma entidade com preponderância nos Conselhos Gerais dos agrupamentos e escolas não agrupadas observadas. No que concerne às escolas privadas e profissionais, este tipo de análise não pode ser elaborado, uma vez que a estrutura organizacional é diferente nessas tipologias de ensino.

Somente metade dos PEs refere a existência de planos direcionados para a relação com a comunidade. Há menção a planos para "aprofundar a ligação do agrupamento com a comunidade" (Ag1), "criar infraestruturas que permitam desenvolver e participar em projetos ecológicos, incluindo parceiros da comunidade em geral" (Ag2), "disponibilizar os espaços da escola à comunidade" (Ag2), "dinamização de atividades por elementos da comunidade" (Ag3), mas talvez a mais significativa, pelo maior número de ocorrências, seja a "divulgação, junto da comunidade, das atividades promovidas pelo agrupamento" (Ag1, Ag4).

Apenas 33\% dos agrupamentos e escolas não agrupadas invoca as respetivas parcerias na sua missão ou visão. "Aprofundar a ligação com a comunidade" (Ag1), "merecer o reconhecimento da comunidade" (Ag2), "contribuir para o desenvolvimento da comunidade" (Ag4) e "adesão a projetos internacionais" (Ag5) são as principais referências, no entanto, a mais significativa é "melhorar a divulgação junto da comunidade" (Ag1). Um número significativo de agrupamentos (42\%) refere a existência de parcerias, mas não as menciona na missão ou visão do PE.

No que concerne a objetivos, $67 \%$ dos PEs faz referências concretas relacionadas com parceiros. As mais usuais são "reforçar parcerias" (Ag3, Ag4, Ag5), "aprofundar relações" (Ag4), "contribuir para o desenvolvimento da comunidade" (Ag4), "abrir as escolas à comunidade" (Prof2), "dinamização cultural" (Ag7) e "promoção da cidadania no meio envolvente" (Ag7). Também vale dizer que 17\% dos agrupamentos e escolas que referem a existência de parcerias não menciona objetivos relacionados com elas nos seus PEs.

As citações integradas nos parágrafos acima, relacionadas com objetivos, planos e missão/ visão, remetem para o plasmado em vários decretos anteriormente referidos, mas principalmente para o DL 137/2012 de 2 de julho, mormente quando, no seu preâmbulo refere "o reforço da abertura à comunidade".

Praticamente todas os PEs referem a ligação à comunidade como uma potencialidade, oportunidade ou ponto forte, sendo que a mais evidente é a existência da própria parceria. Para além desta, mencionam ainda o "trabalho em rede com a comunidade local" (Ag1), a "participação em projetos de dimensão regional, nacional e internacional" (Ag1, Ag2), a "criação de emprego no Conselho" (Ag7), entre outras menos referidas. Não havendo qualquer caso que seja transversal a todas, é possível 
isolar a "participação em projetos de dimensão regional, nacional e internacional" como a potencialidade, oportunidade ou ponto forte mais comum entre as várias escolas e agrupamentos (Ag1, Ag2). Destaca-se aqui a preocupação das escolas em desenvolver ações que liguem a escola à comunidade reconhecendo o seu potencial nas dinâmicas escolares.

Apenas três PEs (25\%) referem fragilidades, fraquezas ou ameaças relacionadas às parcerias. A quase totalidade das referências está ligada à pouca rentabilização das parcerias existentes, mas há também menção a pouca visibilidade externa da escola e a debilidades no processo de comunicação interna e externa. Não havendo também aqui qualquer caso que seja transversal a todos, é possível isolar a fraca visibilidade e a débil comunicação com as parcerias como a fragilidade, fraqueza ou ameaça mais comum entre as várias escolas e agrupamentos. Curioso é que um dos PE englobados nesta análise não refere a existência de parcerias.

A tabela 3 é ilustrativa das constantes ocorrências, nos PEs das fragilidades (incluindo fraquezas e ameaças) e potencialidades (incluindo oportunidades e pontos fortes) das relações da escola com o exterior, assim como as parcerias referidas nas secções - objetivos, missão/visão, planos ou ações concretas orientadas para a comunidade envolvente.

Tabela 3 - Referências a fragilidades, potencialidades, objetivos, missão/visão e planos relacionados com parcerias e/ou orientados para a comunidade

\begin{tabular}{|c|c|c|c|c|c|c|c|}
\hline 山् & & $\begin{array}{l}\frac{\tilde{\pi}}{0} \\
\frac{\pi}{0} \\
\frac{\bar{\sigma}}{\bar{\sigma}} \\
\frac{\pi}{4}\end{array}$ & 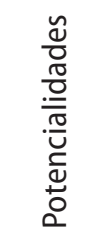 & 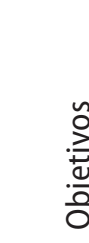 & &  & $\begin{array}{l}\tilde{O} \\
\frac{\pi}{\alpha}\end{array}$ \\
\hline $\mathrm{Ag} 1$ & 0 & 2 & & 0 & 2 & & 3 \\
\hline Ag2 & 0 & 1 & & 0 & 0 & & 3 \\
\hline Ag3 & 4 & 3 & & 2 & 0 & & 1 \\
\hline $\mathrm{Ag} 4$ & 1 & 2 & & 4 & 3 & & 4 \\
\hline Ag5 & 0 & 4 & & 1 & 3 & & 1 \\
\hline Ag6 & 0 & 1 & & 3 & 0 & & 0 \\
\hline Ag7 & 0 & 2 & ? & 3 & 0 & & 0 \\
\hline Pri1 & 0 & 3 & 3 & 9 & 0 & & 0 \\
\hline Pri2 & 0 & c & 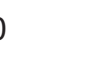 & 0 & 0 & & 0 \\
\hline Pri3 & 0 & c & 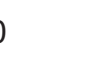 & 0 & 0 & & 0 \\
\hline Prof1 & 2 & 4 & & 1 & 0 & & 0 \\
\hline Prof2 & 0 & 0 & 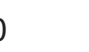 & 2 & 1 & & 1 \\
\hline
\end{tabular}

Fonte: elaborado pelo autor 


\section{Considerações Finais}

A primeira conclusão que pode retirar-se deste estudo, no que diz respeito ao seu objetivo principal, observar as relações com a comunidade, levanta-se o fasto de os PE dos agrupamentos e escolas não agrupadas do conselho em análise serem muito heterogêneos, tanto na forma como no conteúdo. Assim, é possível afirmar que nem todas as escolas se preocupam em plasmar nos PEs as parcerias que estabeleceram com a comunidade envolvente, embora a lei exija o "apoio e a participação alargada da comunidade na vida da escola", como é mencionado no preâmbulo do DL no 172/91 de 10 de maio. Pode afirmar-se até que o número médio de referências a parcerias e protocolos estabelecidos com entidades pertencentes à comunidade envolvente é muito reduzidoquando comparado, por exemplo, aos números totais da escola com maior expressão a este nível.

No entanto, há vários PEs que, não só referem a existência de parcerias, como vão bastante além da mera referência, enquadrando-as nos seus objetivos, visão e metas institucionais e aludindo até a planos de ação direcionados especificamente para a comunidade envolvente, o que prova a importância de tais relações. Neste sentido, os PEs analisados parecem ir ao encontro do artigo 9. do DL 75/2008 de 22 de abril, no qual se explicitam os princípios, os valores e as metas, bem como a comunicação da missão e das metas da escola (Art. $9 .^{\circ}$ - A n. ${ }^{\circ}$ 2, alínea a) aditado pelo Art. ${ }^{\circ} 3 .^{\circ}$ do DL 137/2012). Porém, parecem descorar as estratégias "segundo os quais o agrupamento de escolas ou escola não agrupada se propõe cumprir a sua função educativa".

Em relação à segunda questão de investigação, pode afirmar-se, tendo em consideração apenas os dados observados, que, em termos gerais, são os agrupamentos públicos que dão mais relevância às parcerias, em resposta ao DL no 137/2012, de 2 de julho, particularmente no que respeita ao "reforço da abertura à comunidade". Apesar disso, a escola que refere mais parcerias e mais variadades destas pertence ao ensino privado. Uma maioria larga dos PEs associam as suas parcerias a potencialidades, oportunidades ou pontos fortes, em contraposição com o reduzido número de PEs que as associam a fragilidades, fraquezas ou ameaças. Estes dados cruzam-se diretamente com as potencialidades supracitadas no enquadramento teórico de uma escola sem muros. Parece que, apesar de as escolas reconhecerem a qualidade da prestação das parcerias, nomeadamente nas áreas da saúde, apoio social e apoio psicológico, evidenciam alguma dificuldade em expor as novas dinâmicas escolares nos PE. Na mesma linha das observações anteriores, é possível afirmar que são os agrupamentos públicos que mais fazem menção positiva a esta associação.

Ao longo do desenvolvimento deste estudo, deparou-se com algumas limitações que seguidamente se enunciam. Em primeiro lugar, encontraram-se várias debilidades e inconsistências na construção de alguns dos PEs analisados, falhas essas que vão desde a desatualização ao conteúdo insuficiente. Possivelmente ainda serão vistos, por alguns agrupamentos de escolas, como um "ritual legitimador" (Costa, 1997, pp. 198-199), como um mero documento "simbólico" que tem o objetivo de 
"garantir a "legitimidade externa" (Costa, 2004, p. 95). Sublinha-se que estes documentos foram obtidos das páginas web dos agrupamentos e escolas envolvidas na análise. Em segundo lugar, os dados obtidos mostraram-se demasiado desgarrados e de difícil convergência, resultando numa fragilidade que remete investigações mais alargadas, talvez ao nível de um distrito ou região.

As inconsistências e debilidades detetadas nos PEs remetem ao aumento da formação específica para os responsáveis pela sua construção. Nas escolas públicas, antes da aprovação em conselho pedagógico (artigo 33 do DL n 137/2012, de 2 de julho), a discussão dos PEs passa pela generalidade dos professores, em contexto de reunião de departamento. Esta situação, desejável pela variedade de experiências, sensibilidades e opiniões, poderá não o ser na realidade, uma vez que muitos docentes, não se sentindo motivados e com competências específicas para essa função, se escondem no grupo, ficam alheios à discussão, diminuindo assim os níveis de participação efetiva.

A falta de divulgação do plano estratégico junto da comunidade envolvente remete para maiores preocupações com a comunicação. Há, na realidade, um lote considerável de agrupamentos e escolas que, a avaliar apenas pelo conteúdo disponibilizado nas suas páginas oficiais e pela atividade nas redes sociais, demonstram pouca preocupação com a comunicação com o exterior. Sem estudo que o comprove, fica-se com a sensação de que, a este nível, as escolas privadas, talvez motivadas pela concorrência feroz existente no setor, estão num patamar consideravelmente superior aos agrupamentos públicos.

Considera-se que a investigação realizada constituirá um bom ponto de partida para futuras investigações. A primeira, já aventada acima, prende-se com o alargamento da amostra a um distrito ou região, de forma a melhorar a convergência dos dados e a consistência das informações geradas. Em segundo lugar, tendo em conta as conclusões e limitações anteriormente expressas, considera-se que seria interessante fazer o cruzamento dos dados obtidos do corpus latente com os restantes documentos estruturantes dos agrupamentos e escolas, principalmente com o plano de atividades e com registos eletrônicos retirados das redes sociais, de forma a averiguar até que ponto o plasmado nos PE corresponde ao que realmente acontece no dia a dia das escolas.

\section{Referências}

AFONSO, A.; ESTEVÃO, C.; CASTRO, R. Projectos Educativos, Planos de Actividades e Regulamentos Internos: Avaliação de uma Experiência. Porto: ASA, 1999.

BARDIN, L. Análise de conteúdo. Lisboa: Edições 70, 2009.

BARROSO, J. Relatório Global da Primeira Fase do Programa de Avaliação Externa. Lisboa, 2001

BREMER, J.; MOSHZISKER, M. V. Escola sem Muros: a revolução Pedagógica o Programa Parkway de Fila. São Paulo: Ibrasa, 1975. 
COSTA, J. A. $\mathbf{O}$ projecto educativo da escola e as políticas educativas locais : Discursos e Práticas. Aveiro:UA Editora, 1997.

COSTA, J. A. Projectos educativos das escolas: um contributo para a sua (des)construção. Educação \& Sociedade, v. 24, n. 85, dezembro/2003, p. 1319-1340.

COSTA, J. A. Construção de projectos educativos nas escolas: traços de um percurso debilmente articulado. Revista Portuguesa de educação, v. 17, n. 2, 2004, p. 85-114.

COUTINHO, C. P. Metodologia de Investigação em Ciências Sociais e Humanas: Teoria e Prática, $2^{\text {a }}$ ed. Lisboa: Almedina S.A, 2019.

Decreto-Lei n. ${ }^{43 / 89}$ de 3 de fevereiro, Diário da República n. 29/1989, Série I de 1989-02-03.

Decreto-Lei n 172/91 de 10 de maio, Diário da República n. 107/1991, Série I-A de 1991-05-10.

Decreto-Lei n. 115-A/98 de 4 de maio, Diário da República n. 102/1998, 10 Suplemento, Série I-A de 1998-05-04.

Decreto-Lei n. 6/2001 de 18 de janeiro, Diário da República n. 15/2001, Série I-A de 2001-01-18.

Decreto-Lei n. 75/2008 de 22 de abril, Pub. L. n. 79, Diário da República, Série I-A — n. 792341.

Decreto-Lei n. 224/2009, Diário da República n. 177/2009, Série I de 2009-09-11.

Decreto-Lei n. 137/2012 de 2 de julho, Diário da República n. 126/2012, Série I de 2012-07-02.

DELGADO, J. M.; MARTINS, É. Autonomia, Administração e Gestão das Escolas Portuguesas 19741999: Continuidade e Rupturas. Lisboa: Ministério da Educação, 2001.

Despacho n. 8/SERE/89 de 3 de Fevereiro, publicado a 8 de Fevereiro de 1989, Diário da República - II Série, n. ${ }^{\circ} 32$ Suplemento, de 08.02.1989.

DIAS, M. O. O vocabulário do desenho de investigação: A lógica do processo em Ciências Sociais. Viseu: Psico \& Soma, 2009.

FORMOSINHO, J. A renovação pedagógica numa administração burocrática centralizada. 0 Ensino, v. 7, n. 10, 1984, p. 101-107.

Lei de Bases do Sistema Educativo - Lei n. ${ }^{\circ}$ 46/86 de 14 de outubro, Diário da República n. 237/1986, Série I de 1986-10-14.

LEITE, C.; PRECIOSA, F.; MOURAZ, A.; SAMPAIO, M. Parcerias entre a Escola e a Comunidade em Portugal: Uma Análise a partir da Avaliação Externa das Escolas. Revista Scielo, v. 58, n. 3, 2015, p. 825-855.

MAGALHÃES, P.; MORGADO, J.C. OTerritório como espaço de novas aprendizagens. Revista de Estudios e Investigación en Psicología y Educación, v. 05, 2017, p. 5-7.

PARO, V. H. Crítica da estrutura da escola. São Paulo: Cortez, 2011.

QUIVY, R., VANCAMPENHOUDT, L. Manual de investigação em ciências sociais, $5^{\text {a }}$ ed.. Lisboa: Gradiva, 2008. 
Um olhar qualitativo sobre as parcerias latentes em projetos educativos

SIMON, H. As ciências do Artificial. Coimbra: Arménio Amado, 1981.

YIN, R. Estudo de Caso: Planejamento e Métodos, 5a ed. Porto Alegre: Bookman, 2015. 